\title{
Desposesión de vivienda por turistización? Revalorización y desplazamientos en el Centro Histórico de Palma (Mallorca)'
}

\author{
Sònia Vives-Miró² y Onofre Rullan ${ }^{3}$
}

\begin{abstract}
RESUMEN
A raíz de la actual crisis urbana desatada tras el estallido de la burbuja inmobiliaria, la población española está sufriendo un acelerado proceso de desposesión de vivienda. Los desahucios de inquilinos y las ejecuciones hipotecarias dibujan un escenario conflictivo, que al mismo tiempo activa nuevas oportunidades de acumulación en el entorno construido. Este artículo plantea una discusión sobre el papel que está jugando la desposesión de vivienda a través de los desahucios en el proceso de revalorización y turistización urbana, partiendo de la hipótesis que su correlación deviene necesaria en el proceso de acumulación por desposesión de vivienda. El trabajo se aterriza en el Centro Histórico de Palma, analizando su proceso de turistización y su geografía de los desahucios y revalorización desde los años de auge inmobiliario hasta la actualidad. Se concluye planteando que la turistización como elemento de creación de expectativas de renta, por tanto, potenciadora de la rent gap y en consecuencia de la revalorización inmobiliaria, representa un factor fundamental en la generación de desplazamientos directos.
\end{abstract}

Palabras clave: Desposesión de vivienda, desahucios, renta urbana, turistización, Palma.

\begin{abstract}
Due to the current crisis brought on by the bursting of the real estate bubble, the Spanish population is rapidly undergoing a process of home dispossession. The eviction of tenants and mortgage foreclosures create a very unsettling social urban environment. But, at the same time, these conflicts generate opportunities for accumulating structures through new financial engineering. This paper raises a discussion about the role that home dispossession is playing through evictions in the process of revaluation and urban touristization, starting from the hypothesis that its correlation becomes necessary in the process of accumulation by home dispossession. The study is landed in the Historic Center of Palma, analyzing its process of tourisyization and its geography of evictions and revaluation from the years of real estate boom to the present. It is concluded that touristization as an element of creation of urban rents expectations, therefore, potentiating the rent gap and as an element of creation of urban rent expectations, thus enhancing the rent gap and, as a consequence of the real estate revaluation, represents a fundamental factor in the generation of direct displacements.
\end{abstract}

Keywords: Home dispossession, eviction, urban rent, touristization, Palma.

El presente trabajo ha contado con la ayuda de los proyetos de investigación del Plan Nacional de I+D+l del Ministerio de Economía y Competitividad: "Crisis y vulnerabilidad en ciudades insulares españolas: transformaciones en los espacios de reproducción social" (CSO201568738-P) (MINECO/FEDER) y "Nuevos Modelos De Gobierno De Las Ciudades, e intervención en los espacios urbanos en el periodo postcrisis (ref. CSO 2016-75236-c2-1-r)". Artículo recibido el 8 de mayo de 2016, aceptado el 23 de septiembre de 2016 y corregido el 22 de diciembre de 2016.

Universidad de Santiago de Compostela (España).E-mail: so.vives@gmail.com

Universidad de las Islas Baleares (España). E-mail: orullan@uib.es 
El estallido de la última burbuja inmobiliaria y la consecuente entrada en la crisis financiera ha inmerso a las ciudades españolas en un intenso proceso de desposesión de vivienda. Un proceso en el que la desigualdad social se acentúa, marcando una clara polarización entre los beneficiados y los perjudicados de la reestructuración económica y urbana. Son los propietarios de vivienda, especialmente la banca, aquellos que a través de las estrategias implantadas como solución a la crisis se han apropiado de las rentas urbanas. Sin embargo, los principales perjudicados están siendo los estratos sociales más precarizados, aquellos no propietarios de bienes inmuebles. En resumen, la oleada española de desahucios de inquilinos y ejecuciones hipotecarias dibuja un nuevo escenario social que desata el conflicto social.

La ola de ejecuciones hipotecarias desatada desde 2008 muestra como los desahucios resueltos por los juzgados españoles no superaban los 20.000 anuales antes de la crisis y que, en la actualidad, superan los 70.000 aunque las moratorias de $2012^{4}$ y $2013^{5}$ están conteniendo ligeramente las cifras (Méndez et al., 2014). En cualquier caso las cifras sobre ejecuciones hipotecarias no reflejan los desahucios de inquilinos tras los impagos de alquiler, tan solo las ejecuciones hipotecarias ejercidas sobre aquella población que se había lanzado a adquirir una vivienda en propiedad y que, en tiempos de crisis, no puede hacer frente a las cuotas exigidas por las hipotecas. Los desahucios de inquilinos suponen un conflicto que no ha trascendido tanto a los medios de comunicación como las ejecuciones hipotecarias pero que, como se verá, es cuantitativamente mucho más importante.

Pero la crisis urbana para otros agentes abre nuevas oportunidades de acumulación vinculadas al entorno construido. Se trata de operaciones que se articulan a través de nuevas ingenierías financieras que aprovechan, o incluso programan, procesos de desvalorización y posterior revalorización en el que los desahucios de inquilinos y ejecuciones hipotecarias permiten ajustar la nueva oferta de vivienda a la demanda de estratos sociales de mayor poder adquisitivo. Un proceso que, en su momento, ya recogió y explicó la teoría de la rent gap (Smith, 1979). Estos procesos, en entornos construidos de alto valor patrimonial como el que analizaremos, pueden verse favorecidos, además, por la implantación de usos turísticos y vacacionales que, al provocar el aumento de precios, chocarán directamente con los intereses de los residentes de menor poder adquisitivo.

A partir de estos planteamientos previos, este trabajo quiere abrir una discusión sobre el papel que está jugando la desposesión de vivienda a través de los desahucios de inquilinos y de las ejecuciones hipotecarias en el proceso de revalorización y turistización urbana. Para ello se pretenden analizar las relaciones existentes entre la revalorización del parque inmobiliario, la turistización y la desposesión de vivienda por desahucios de inquilinos y ejecuciones hipotecarias en el caso del Centro Histórico de la ciudad de Palma (Islas Baleares). Se parte de la hipótesis que la correlación entre estas variables deviene clave en el proceso de acumulación por desposesión de vivienda, siendo necesarios los desahucios para la revalorización y la turistización del barrio objeto de análisis.

Para abordar estas cuestiones, en primer lugar, se lleva a cabo una discusión teórica entre las relaciones que derivan de los desplazamientos, turistización y financiarizacion. En segundo lugar,

http://www.boe.es/diario_boe/txt.php?id=BOE-A-2012-14115

http://www.boe.es/diario_boe/txt.php?id=BOE-A-2013-5073 
como caso de estudio, se analiza el proceso de revalorización, turistización y de desahucios de inquilinos y ejecuciones hipotecarias del Centro Histórico de la ciudad de Palma (Mallorca, España), tratando de desenmarañar las relaciones que se establecen entre dichos procesos. Por último se plantean algunas conclusiones que desembocan en el entendimiento del rol de los desahucios como un activo para la turistización y revalorización urbana.

\section{Desposesión de vivienda por revalorización: turistización y financiarización del entorno construido}

En este trabajo se aborda la cuestión de la desposesión de vivienda en general y de los desahucios en particular como un aspecto inherente a la producción y captura de renta urbana. Huimos, por tanto, de aproximaciones que contemplan la cuestión en términos de impactos, efectos, daños colaterales, etc., que normalmente acompañan la narrativa académica sobre estas cuestiones en que la "pérdida de vivienda" o la "dificultad de acceso a la vivienda" de los "sectores más vulnerables" es contemplado como una especie de desgracia o accidente técnico que se debe corregir o paliar.

El enfoque teórico se fundamenta en el marco de lo que David Harvey (2003) acuñó como home dispossession dentro de la más genérica acumulación por desposesión que cierra y concluye los procesos de inversión del capital en el entorno construido, los procesos de urbanización del capital. Harvey propone el concepto como actualización de la acumulación originaria que condujo a la articulación de los llamados cercamientos históricos de los que hablaba Marx (1990 [1864]) y que, en su momento desvinculó los productores de sus medios de producción. Aquellos primitivos cercamientos siguen manifestándose hoy día bajo nuevas formas y fórmulas que ha hecho aflorar la reestructuración postfordista del sistema capitalista (Midnight Notes Collective, 1990). Consumada la separación/cercamiento entre productores y medios de producción, la nueva ronda de despojos afecta ahora, especialmente en los países sur europeos, a la reproducción social: educación, salud y la vivienda. Privatizaciones y, como en el caso que nos ocupa, desposesiones de vivienda concretan esta última ronda que, en la ciudad se ha materializado a través del llamado urbanismo neoliberal (Smith, 1996).

Si bien la acumulación de renta urbana a través de la vivienda está muy trabajada en la literatura académica, su desposesión como parte inherente al proceso de acumulación no ha atraído tanta atención. Este artículo se enfoca considerando indesligable la desposesión de vivienda que suponen los desahucios de los procesos de acumulación de rentas urbanas. Ambos procesos son las dos caras de una misma moneda.

En este sentido, abordamos la dinámica de la desposesión de vivienda que conllevan los procesos de acumulación que comprenden, por un lado, la financiarización urbana como lógica imperante el contexto actual de las ciudades y, por otro, el añadido de la turistización que acentúa el mismo proceso en nuestro ámbito de estudio.

En relación con la financiarización de la vivienda, la abundante literatura crítica que se ha publicado en los últimos años coincide en su inserción en los estudios, más generales, sobre financiarización del entorno construido (Clark \& Hansen, 2012). La vinculación entre la financiarización 
(Krippner, 2005) y el espacio urbano la detectamos en el momento de la conversión del suelo en activo financiero y, consecuentemente, su inserción en la circulación de los capitales financieros tanto nacionales como internacionales. Este aspecto recupera la idea de la "tierra como un activo financiero" (Harvey, 1982) que supone la mercantilización y compraventa de derechos expectantes potenciales de negocio inmobiliario, independiente del suelo o la tierra considerados en sí mismos (Harvey, 1982). En las últimas décadas se ha asistido a la expansión de las inversiones de capital y financieras en el entorno construido dirigida directamente a conseguir un mejor valor de cambio. En otras palabras, se ha incrementado sobremanera la expectativa de renta potencial (Clark \& Hansen, 2012). De esta manera, una mayor expectativa de renta potencial conduce a una inminente revalorización del entorno construido y, por supuesto, de la vivienda.

Por otra parte la expansión de la turistización, en sus múltiples vertientes, representa otro mecanismo de extracción de renta que, en determinados contextos, puede potenciar la revalorización inmobiliaria y, consecuentemente, animar las posibilidades de extracción de renta urbana a través del entorno construido de uso residencial. Sin embargo este planteamiento exige enfocar el turismo desde la óptica de la oferta y no, como comúnmente hacen los enfoques más ortodoxos, desde la demanda al pregonar la soberanía del cliente/turista. Otros autores (Agarwal et al., 2000; Ioannides, 1995; Tremblay, 1998) señalan como la oferta turística responde a cambios estructurales que modifican la producción y a los que debe adaptarse la demanda. Estos autores huyen de explicaciones motivacionales de los turistas para explicar la producción turística resaltando el poder de la oferta donde la financiarización, promoción y publicidad se erigen como factores claves para entender el fenómeno. Éste es el enfoque que se adopta en este trabajo y que nos servirá para relacionar el turismo urbano del centro Histórico de Palma con parte de los desahucios.

Por tanto, la relación de los processos de financiarización y turistización como procesos de acumulación que comportan la desposesión de vivienda recae en el común denominador del fomento del incremento del potencial de renta urbana. Es decir, ambos constituyen procesos que revalorizan el entorno urbano y, por tanto, excluyen de vivienda a determinadas capas sociales.

A menudo, pero sobretodo en los centros históricos, el aumento de la renda potencial significa un incremento de la rent gap. La rent gap se ha definido como "la diferencia entre el nivel de la renta potencial del suelo y la renta actual capitalizada del suelo bajo el actual uso del suelo" (Smith, 2012: 126). Potencialidad, por tanto, de la renta del suelo, frente a la renta real determinada por la intensidad y uso del momento (Clark, 1995: 1490). La desinversión que padecen algunos antiguos barrios centrales implica un sostenido descenso de precios del suelo que, al alcanzar un determinado nivel hace atractiva la posible reinversión que entonces deviene rentable. En este momento los promotores pueden hacerse con un excedente lo suficientemente apetecible. Mediante este proceso es como se activa la gentrificación (Smith, 2012). Pero la gentrificación, más allá de a través de la apropiación de renta urbana, se define por los desplazamientos que conlleva.

No obstante, Tom Slater advirtió que los desplazamientos que provoca la gentrificación habían prácticamente desaparecido del enfoque académico (Slater, 2015). Tal olvido se ha pretendido en ocasiones por su difícil cuantificación (Newman \& Wyly, 2006) o, en otras, por tratarse de una "medición de lo invisible" (Atkinson, 2000). Tom Slater, recuperando a Peter Marcuse (2010), insiste en la necesidad de corregir aquel olvido "para restablecer las perspectivas críticas" (Slater, 2015: 131). De acuerdo, por tanto, con la advertencia que hace Slater entendemos los desahucios 
de inquilinos como desplazamientos vinculados a la gentrificación. Siguiendo a Slater y especialmente a Marcuse debemos encuadrar los desahucios de inquilinos en lo que este último autor llamó desplazamientos directos, distinguiendo entre los del último residente y en cadena (Marcuse, 1985) ${ }^{6}$. Consideramos que los desahucios de inquilinos, como desplazamientos directos por causas económicas, forman parte del proceso de la producción de renta urbana que describe la teoría de la rent gap. En consecuencia los consideramos como parte fundamental en la estrategia de producción o captura de renta urbana. Esta integración conceptual refuerza, pensamos, el entendimiento más genérico del fenómeno.

\section{Metodología y Fuentes}

Para llevar a cabo el análisis del proceso de valorización del entorno construido residencial del Centro Histórico de la ciudad de Palma se ha cartografiado la evolución de los precios de la vivienda (años 1991, 2006 y 2015) a partir de anuncios en prensa y páginas web inmobiliarias.

Por otro lado se ha cartografiado la evolución de los desahucios de inquilinos y de las ejecuciones hipotecarias desde 2003 hasta 2014 con resolución de dirección postal a partir de fuentes judiciales ${ }^{8}$.

Esta cartografía, respeto a estudios anteriores, localiza no sólo las ejecuciones hipotecarias, lo más habitual en la literatura científica española sobre el tema, sino también los desahucios de inquilinos. Por otra parte el trabajo resulta también novedoso en cuanto a la resolución ya que, cuando se han elaborado cartografías sobre esta temática, la escala normalmente ha sido, como máximo, de partido judicial (Méndez et al., 2014; Obeso, 2014), en nuestro caso llegamos a localizar con resolución de calle y número.

En cuanto a la metodología para la elaboración del mapa de turistización del Centro Histórico de Palma se ha partido de dos fuentes distintas. La oferta de alojamiento turístico hotelero y apartamental se ha obtenido y georreferenciado a partir de los catálogos oficiales ${ }^{10}$. En cuanto a la oferta de alojamiento que se comercializa vía Airbnb los datos, ya georreferenciados, se han obtenido del portal Inside Airbnb ${ }^{11}$. Especialmente importante ha sido la consideración de la nueva oferta de alojamiento de Airbnb, una oferta que ya podemos considerar más importante en el Centro Histórico de Palma que la de la oferta de hoteles y apartamentos y que, como en otras

\footnotetext{
6 El desplazamiento directo del último residente describe los residentes de bajos ingressos desplazados a partir de mecanismes físicos o económicos, mientras que los desplazamientos directos en cadena, más allá del "último residente" desplazado, tiene en cuenta a los hogares que pueden haver sido forzados a mudarse en un determinado período de tiempo (Marcuse, 1985: 205-206).

Para el año 1991 se han obtenidos los datos de la hemeroteca digital de Diario de Mallorca. Para el año 2006 los datos provienen también de Diario de Mallorca además de Trueque y Segunda Mano. Y para 2015, Fotocasa (http://www.fotocasa.es/ca) e Idealista (http://www.idealista.com/ca/)

8 En concreto los datos provienen de los Dietarios del Servicio Común de Notificaciones y Embargos del Partido Judicial de Palma donde figuran las direcciones postales de las viviendas objeto de desahucio de inquilino o de ejecución hipotecaria.

9 En el trabajo de Obeso también se aporta un mapa de Madrid (figura 5) con resolución de calle y número (Obeso, 2014: 339) pero a partir de información proveniente de la Plataforma de Afectados por la Hipoteca, no de fuentes judiciales. Nosotros mismos, en otro trabajo anterior, ya habíamos presentado algunos mapas con localización de desahucios a escala de sección censal y de calle y número (Vives-Miró et al., 2015).

10 En concreto se trata del Catálogo Español de Hoteles (1932-1991) publicado por la administración turística española y del Catálogo de alojamiento turístico (1996-2010) publicado por la administración turística de las islas Baleares.

11 http://insideairbnb.com/mallorca/ [última visita 7/04/2016]
} 
muchas ciudades, se está expandiendo con rapidez. Al tratarse de una actividad que, en gran medida, se escapa del control oficial y su impacto es más que notable en el espacio urbano, se hacía imprescindible su consideración en este trabajo aun a sabiendas que otras plataformas también ofrecen home sharing con transacción económica.

A partir de estos datos de oferta turística se elaboraron los correspondientes mapas mediante Sistemas de Información Geográfica que, posteriormente se han superpuesto y analizado geoestadísticamente.

\section{Turistización, revalorización inmobiliaria, y desposesión de vivienda en el Centro Histórico de Palma}

Para analizar la relación que se establece entre turistización, revalorización y desposesión de vivienda se ha analizado el caso del Centro Histórico de la ciudad de Palma (Mallorca, Islas Baleares). En este espacio se han cartografiado y analizado las variables mencionadas con el fin de constatar su comportamiento geográfico y establecer la relación existente entre cada una de ellas.

\section{La ciudad de estudio: Palma}

La ciudad de Palma (400.578 habitantes en 2015) es la capital de la Comunidad Autónoma de las Islas Baleares (España), un archipiélago que, en 2015 contaba con 1.104 .479 habitantes, más de 400.000 plazas turísticas y más de 10 millones de turistas provenientes, en un $70 \%$, de tres mercados emisores: Alemania, Reino Unido y España. El casco antiguo de la ciudad -con más de 100 has de superficie, más de 22.000 habitantes en 2016 y 1.947 plazas turísticas- se sitúa en el fondo de la bahía del mismo nombre y hasta principios del siglo XX constituía prácticamente el único núcleo del municipio. A partir de entonces la ciudad se expandió hacia el interior (ensanche) y a este y oeste de la bahía (zonas turísticas) hasta conurbarse con los principales municipios vecinos. Hoy, la posición privilegiada del Centro Histórico en primera línea de la bahía y su alto valor histórico-patrimonial lo hacen muy atractivo para todo tipo de usos turísticos y residenciales.

\section{La geografía de la revalorización}

¿Cómo han evolucionado los precios de la vivienda en el casco antiguo de Palma? La geografía de los precios de la vivienda del Centro Histórico de Palma, a principios de la década de 1990, presentaba una clara disimetría entre la parte oriental y la occidental. Pero las diferencias entre ambas partes de la ciudad eran relativamente pequeñas si, como veremos, lo comparamos con lo que ocurrirá en las décadas posteriores. Mientras la parte oriental presentaba precios ${ }^{12}$ inferiores a $10 € / \mathrm{m}^{2}$, la parte occidental presentaba valores entre 14 y $15 € / \mathrm{m}^{2}$ (Figura $\mathrm{N}^{\circ} 1$ ).

El mayor precio inmobiliario del centro histórico occidental se apoyaba, todavía en 1991, en importantes vías urbanas de uso tanto residencial como comercial -el paseo Mallorca y la avenida Jaime III principalmente. Ambas arterias se habían urbanizado en su configuración actual en la década de 1950 como desarrollo de la llamada reforma número 1 del Plan Alomar del 1943 (Alomar,

En todo el artículo se trabaja con precios en euros equivalentes de 2015 
Figura $\mathrm{N}^{\circ} 1$

Precio de la vivienda en el Centro Histórico de Palma en 1991

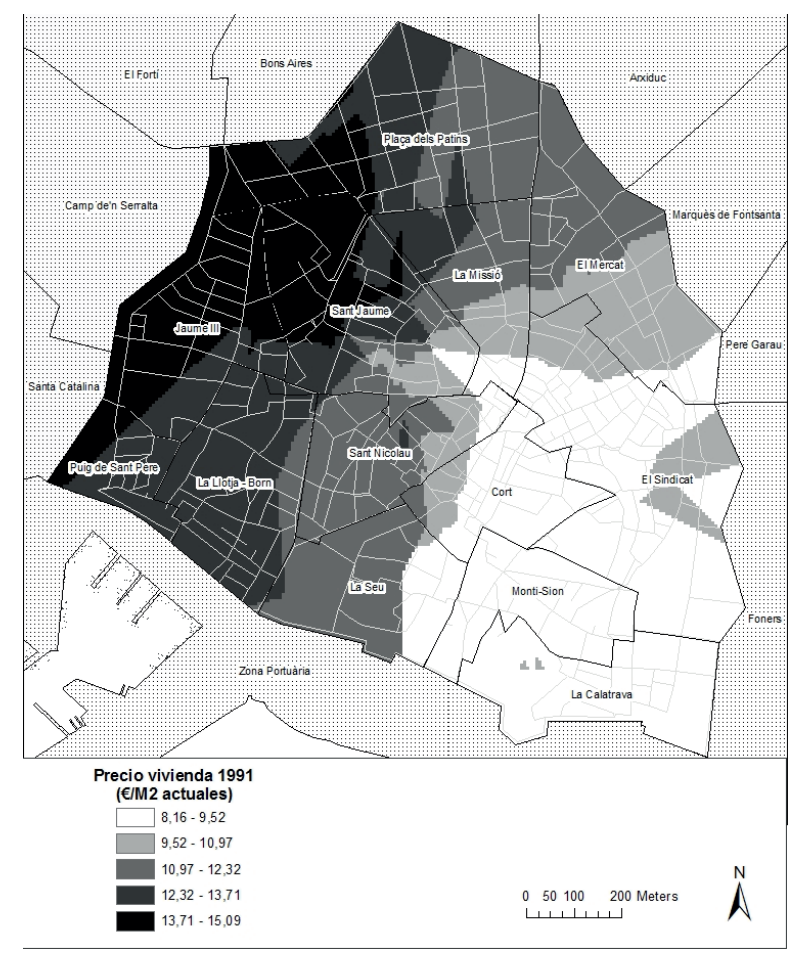

Fuente: Elaboración propia.

2000: 50-51). Dicha reforma planteaba dos tipos de actuaciones diferentes, por un lado urbanizaba el llamado hort d'en Moranta que aún quedaba vacante en el interior de la ciudad preindustrial dando frente a la Riera (paseo Mallorca) y, por el otro, conectaba la nueva urbanización con el eje central de la ciudad histórica (Rambla/Unión/Borne) mediante una operación de sventramento (Jaime III) de clara inspiración hausmanniana (Figura $\mathrm{N}^{\circ} 2$ ).

Figura No 2

La avenida Jaume III en 1952 y en la actualidad

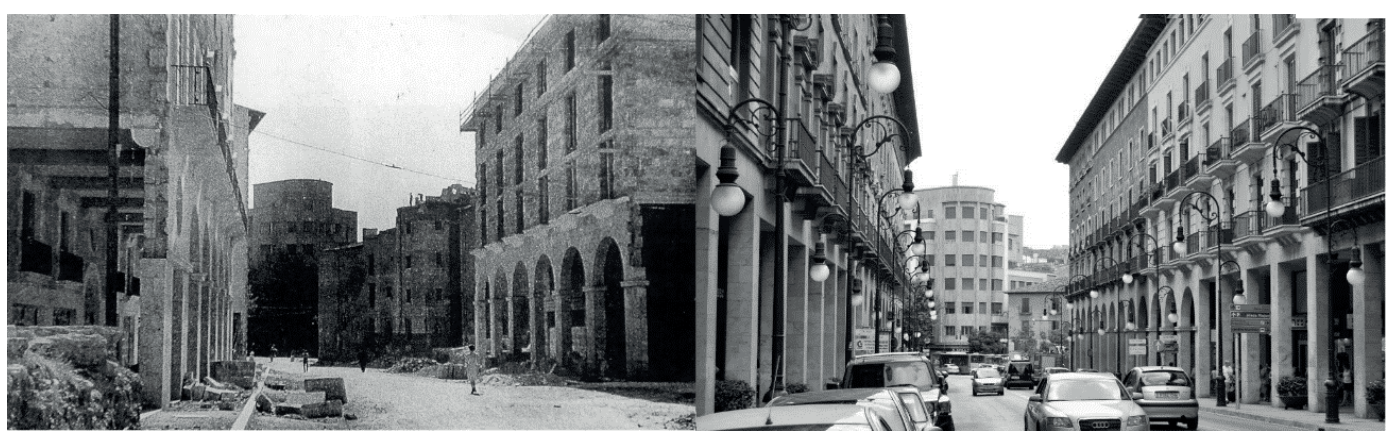

Fuente: http://fotosantiguasdemallorca.blogspot.com.es/2010/11/calles-de-palma.html 
La propuesta urbanística de 1943 no dejaba dudas en cuento a sus objetivos: “Una vez abierta la arteria (...), quedan espléndidamente valorizados estos terrenos, cuya situación es inmejorable, teniendo una extensa fachada al Paseo Mallorca, con vistas al mar" (Alomar, 2000: 50).

A partir de esta operación de reurbanización y valorización, esta zona (Paseo Mallorca/Jaime III) se convertiría en la de mayor valor inmobiliario y comercial de la Palma de las décadas de 1960 y 1970, cuando la economía turística, de localización costera, se iba conformando y el ensanche de la ciudad estaba desplazando la ciudad histórica como área de atracción de población y actividad. Una atracción sólo contrarrestada por la valorización asociada a la reforma número 1 de Alomar.

En la parte occidental de la ciudad también se localizaba un antiguo barrio popular, el Puig de Sant Pere, que el mapa de precios inmobiliarios del 1991 (Figura $N^{\circ} 1$ ) ya muestra cómo se estaba revalorizando. Esta revalorización se debía, en gran parte, a la implementación de decididas políticas públicas de rehabilitación que se concretaron en el que fue el primer Plan Especial de Reforma Interior (PERI) que se aprobó en España (1977) y que 14 años más tarde de su aprobación, en 1991, ya mostraba indicadores de revalorización.

Por su parte, en la zona oriental de la ciudad histórica se concentraban usos como el barrio chino en "la Gerreria" y barriadas como la misma "Gerreria" y "la Calatrava" que estaban en un claro proceso de desvalorización patrimonial y marginalización social. Ambas barriadas, décadas atrás, habían tenido una importante impalantación industrial (Escartín, 2001: 32-59) que, una vez desmantelada la industria, aceleraron la decadencia de ambas barriadas.

Sobre este escenario que dibuja el mapa de precios de 1991 actuaron dos vectores de valorización que generaron movimientos de población y gentrificación. Por un lado se pusieron en marcha unas políticas públicas que hicieron atractivas las inversiones privadas en el sector oriental; por otro, la puesta en valor del frente marítimo más occidental del casco para usos no estrictamente portuarios y vinculados con el ocio y el turismo. Ambas iniciativas fueron promovidas tanto por las distintas administraciones con competencia en la zona (Autoridad Portuaria, Ayuntamiento, gobierno de las Islas Baleares) como por parte de empresas portuarias vinculadas al negocio del ocio y promotoras inmobiliarias.

Las políticas públicas que han afectado al revalorizado sector oriental se concretaron en la aprobación del PERI de "la Calatrava" en 1989 (y especialmente su modificación de 1993), el PERI de "la Gerreria" (el barrio chino) de 1995 y las actuaciones vinculadas al Plan Urban (1997-99) que financió gran parte de las propuestas de los mencionados Planes Especiales (Figura $N^{\circ} 3$ ).

Por su parte el interés por el frente marítimo de la ciudad histórica que manifestaron los inversores privados y las administraciones desde la segunda mitad de la década de 1990 hizo ganar valor inmobiliario en la parte meridional del centro histórico. El Puig de Sant Pere, como ya hemos comentado, se iba revalorizando desde la década de 1980 como consecuencia de políticas públicas de rehabilitación. La parte central del frente marítimo concentraba la imagen más monumental de la ciudad histórica (la Lonja, la Almudayna, la Catedral, el parque de la Mar, el Obispado etc.) siendo el principal foco de atracción turística de la ciudad histórica. Y, por último, la parte más oriental del frente marítimo, que partía de valores inmobiliarios muy bajos, empezaba a ver los efectos de las políticas de inversión privada que se dispararon a partir de la modificación del 
Figura $\mathrm{N}^{\circ} 3$

Los planes especiales de reforma interior (PERIs) y el plan Urban Temple de Palma

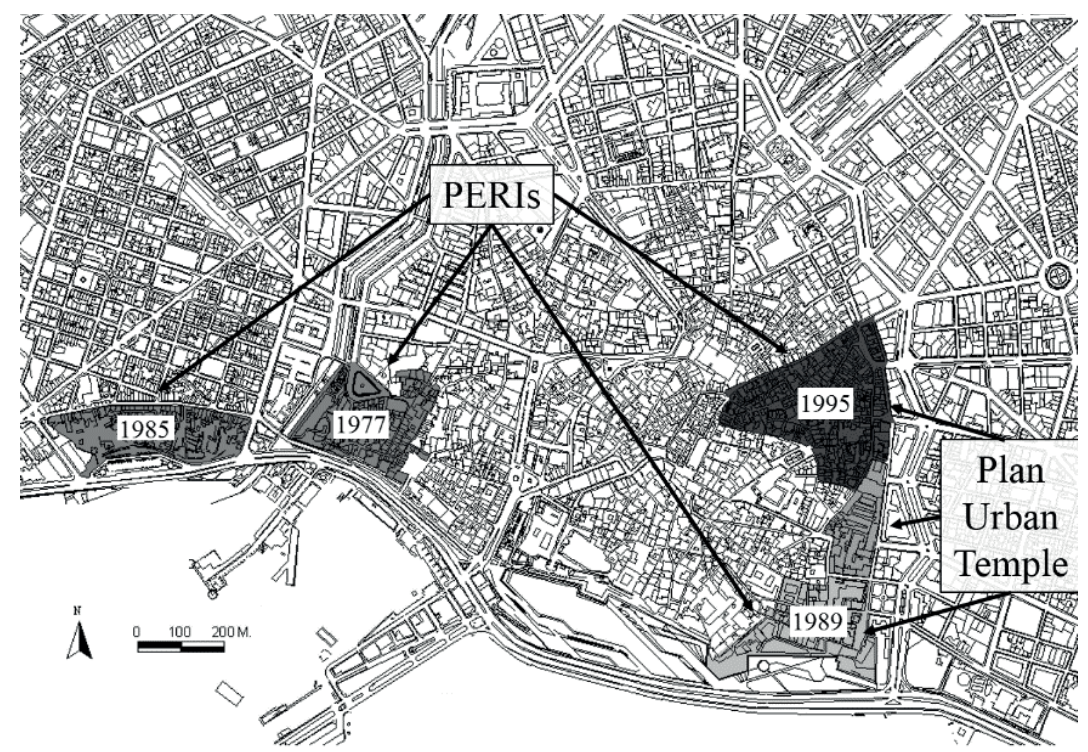

Fuente: Elaboración propia

PERI de la Calatrava (1993) y la afluencia de dinero de inversores consecuencia de la introducción del euro (Franquesa, 2010).

Consecuencia de todo ello es un nuevo mapa de valor inmobiliario que se empieza a perfilar en 2006 y que, en 2015, presentará un claro gradiente norte/sur (Figura $N^{\circ} 4$ ) frente al este/oeste que mostraba el de 1991 (Figura № 1). Si en 1991 se partía de una línea imaginaria norte-sur que separaba el oeste de mayor valor inmobiliario del este de menor valoración, el proceso de cambio observado ha conducido a que, en un cuarto de siglo, aquella línea haya girado 90 grados en sentido anti horario separando, ahora, un centro histórico meridional de mayor valor inmobiliario de la parte septentrional de menor valoración. La subida de precios ha sido muy importante, concentrándose los más elevados en la parte central y oriental del frente portuario ${ }^{13}$ superando $\operatorname{los} 4.000 € / \mathrm{m}^{2}$.

El proceso descrito se sintetiza mejor si comparamos directamente los mapas de precios de 2006 y 2015 (Figura $N^{\circ}$ 5). En el mapa resultante se pueden ver las zonas donde la revalorización inmobiliaria ha sido más intensa en estos 24 años.

En este sector, según informaciones aparecidas en El País (8/06/2007), en 2007 se localizaba la calle más cara de España con precios que, puntualmente, podían alcanzar los $17.000 € / \mathrm{m}^{2}$. 
Figura $\mathrm{N}^{\circ} 4$

Precio de la vivienda en el Centro Histórico de Palma en 2006 y 2015

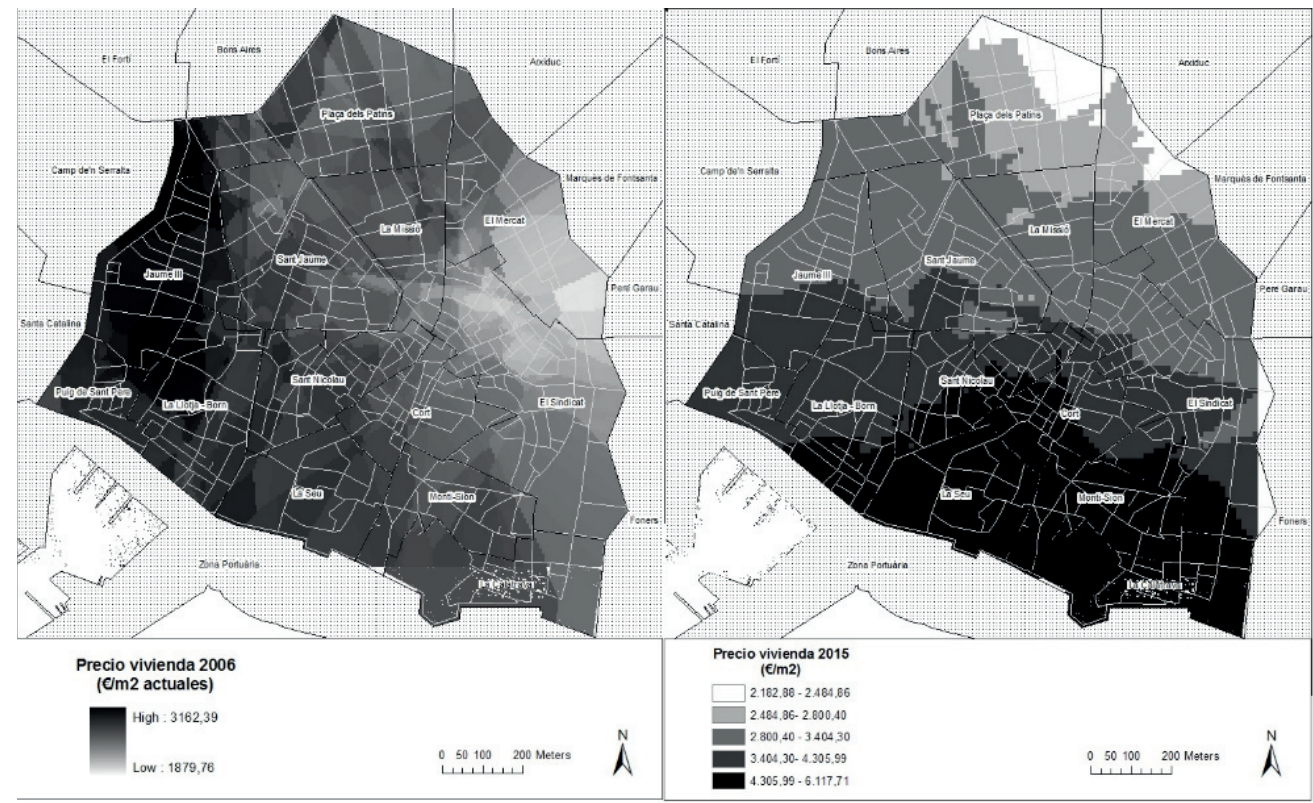

Fuente: Elaboración propia.

Figura $\mathrm{N}^{\circ} 5$

Incremento del precio de la vivienda en el Centro Histórico de Palma entre 2006 y 2015

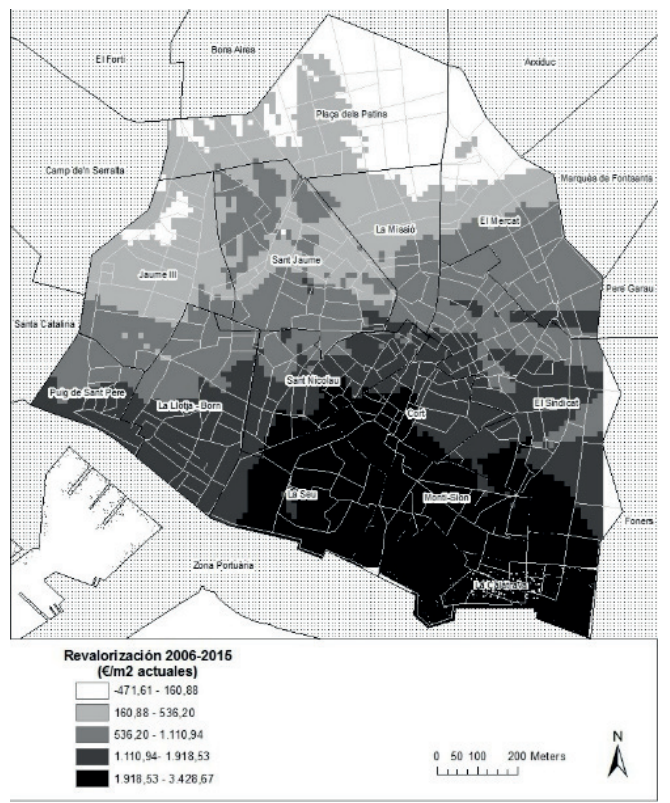

Fuente: Elaboración propia. 
Comparando la evolución de precios entre 2006 y 2015 se observa un comportamiento espacial de la revalorización que se acentúa, especialmente al SE, donde la decadencia industrial y las excelentes vistas sobre la bahía habían abierto la brecha de renta entre lo que se estaba capitalizando y lo que, potencialmente, se podía capitalizar mediante la correspondiente inversión.

Pero esta geografía de la revalorización inmobiliaria ¿qué relación ha tenido con el proceso más general de turistización del Centro Histórico de Palma? Veámoslo.

\section{La geografía de la turistización}

En gran parte de las principales ciudades españolas y, en particular, en sus centros históricos, la función turística está compitiendo y en muchas ocasiones desplazando a los residentes tradicionales, el Centro Histórico de Palma no es ninguna excepción.

Dos son los tipos de alojamientos turísticos que hemos analizado para el caso que nos ocupa: la oferta reglada de hoteles y apartamentos turísticos que aparecen en los catálogos oficiales y la oferta que se comercializa en la plataforma Airbnb. Las cifras globales de ambas ofertas aparecen en Cuadro $N^{\circ} 1$.

Cuadro $N^{\circ} 1$

La oferta de alojamiento en el Centro Histórico de Palma

\begin{tabular}{|c|c|c|c|c|}
\hline & \multicolumn{2}{|c|}{ Hoteles } & \multicolumn{2}{|c|}{ Airbnb } \\
\hline & Número & Plazas & Número & Plazas \\
\hline 2010 & 24 & 1.505 & ? & \\
\hline 2016 & 37 & 1.947 & 745 & \\
\hline
\end{tabular}

Fuente: Elaboración propia.

Como se puede observar, en seis años la oferta de alojamiento hotelero se ha incrementado prácticamente un 30\%. En cuanto a la oferta en Airbnb, aun sin disponer de datos para 2010, sabemos que hay 745 establecimientos que ofrecen este servicio. Se puede afirmar que la oferta en plazas de Airbnb supera a la hotelera ya que tan solo con una hipotética media de tres plazas por alojamiento ya la superaría y, sin duda, esta media es superior ${ }^{14}$. La distribución de ambos tipos de oferta aparece en los mapas de las Figuras $\mathrm{N}^{\circ} 6$ y $\mathrm{N}^{\circ} 7$.

El alojamiento hotelero (Figura $N^{\circ}$ 6) hasta el año 2010 se localizaba preferentemente en la parte occidental del casco antiguo y especialmente en la zona de contacto con la actividad portuaria (oeste). La apertura de hoteles en los últimos 6 años redefine la geografía de la oferta; se intensifica la localización cercana a la actividad portuaria en contacto con la zona de ocio del barrio de la Lonja y se expande por la zona centro-oriental, muy cerca de las zonas de rehabilitación y de mayor revalorización.

Sabemos que la media balear de alojamiento de casas vacacionales regladas según la normativa turística es superior a 6 plazas por establecimiento. 
Figura $N^{\circ} 6$

La oferta hotelera en el Centro Histórico de Palma en 2016

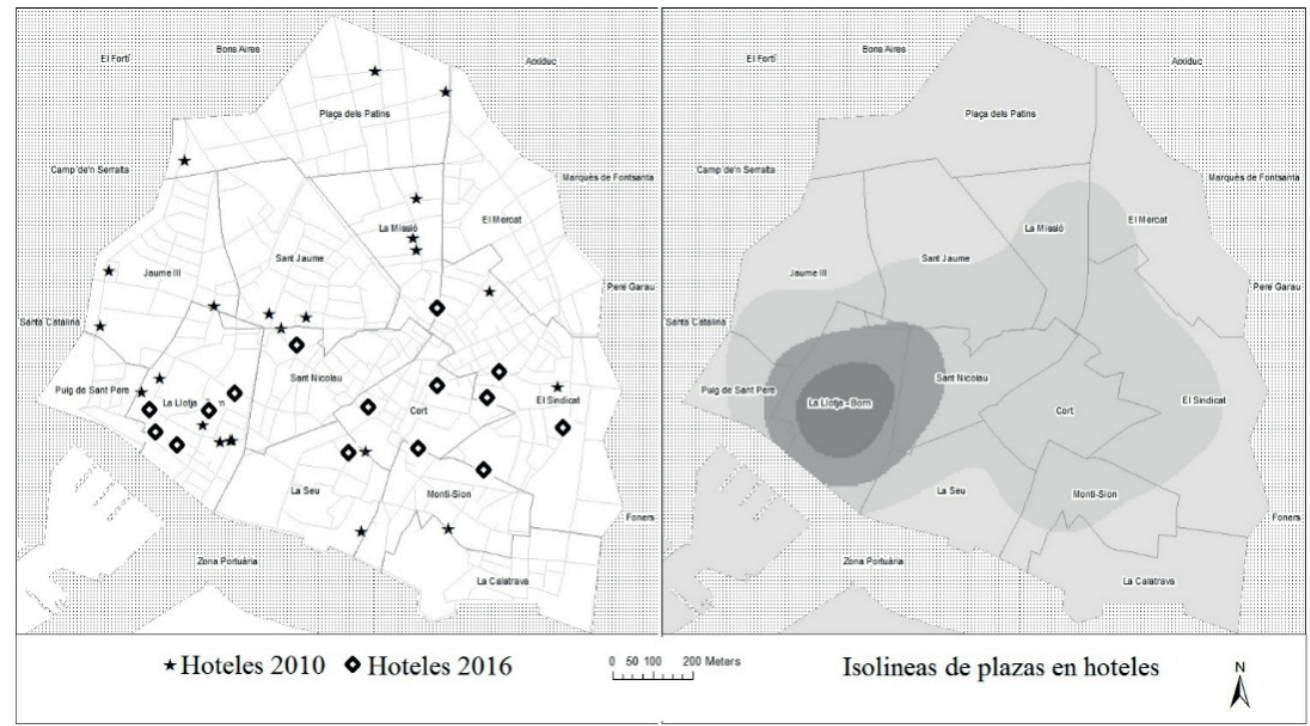

Fuente: Elaboración propia a partir de los catálogos hoteleros oficiales.

La geografía del Airbnb es de distribución mucho más regular al depender de inversiones menores y estar vinculada al parque inmobiliario de particulares. De todas maneras la zona centro-oriental también presenta aquí la mayor presencia de este tipo de oferta (Figura $\mathrm{N}^{\circ} 7$ ).

Figura $\mathrm{N}^{\circ} 7$

La oferta de Airbnb en el Centro Histórico de Palma en 2016

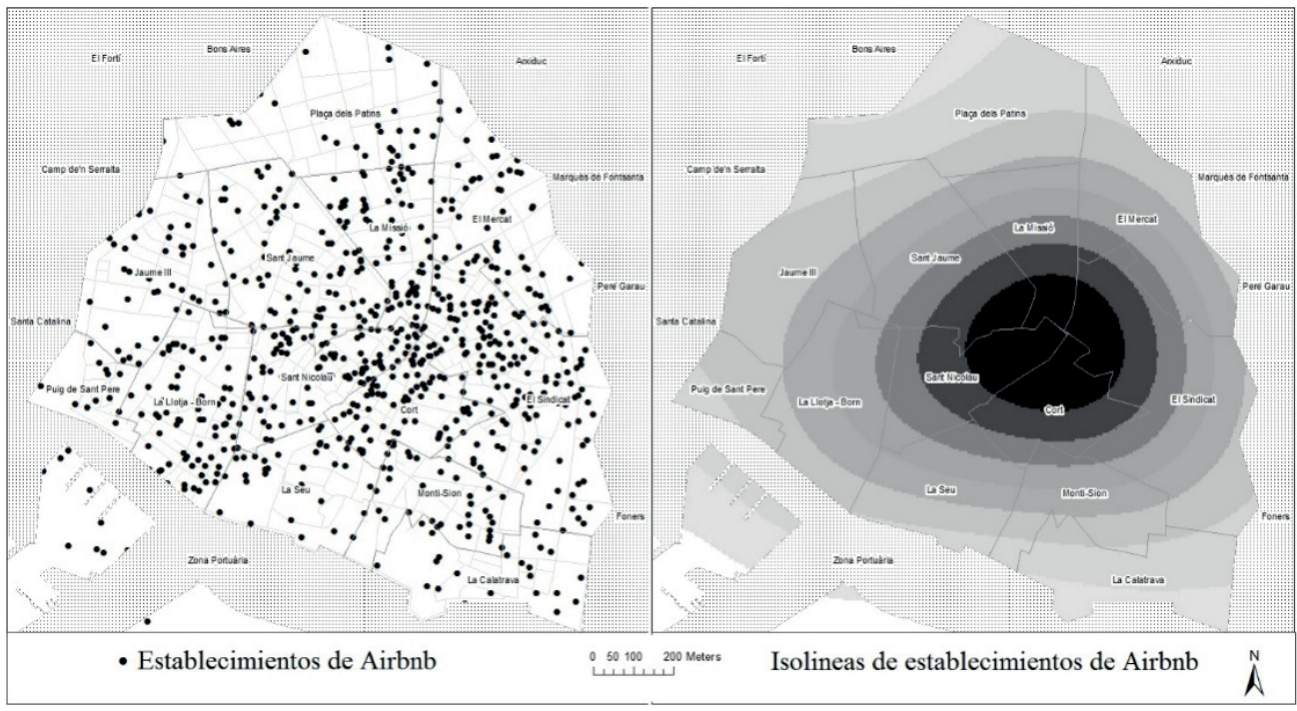

Fuente: Elaboración propia a partir de http://insideairbnb.com/mallorca/ 
Si la revalorización y la expansión de la oferta turística condicionan e influye sobre el sector residencial, dicha influencia debería reflejarse en la geografía de los desahucios. Veamos los parámetros básicos de su distribución geográfica.

\section{La geografía de los desahucios}

En el Centro Histórico de Palma, entre 2003 y 2014, hemos contabilizado un total de 890 desposesiones directas de vivienda, de las cuales 810 corresponden a desahucios de inquilinos y sólo 80 a ejecuciones hipotecarias. Desde que estalló la crisis se contabilizan el 62,32\% del total (Cuadro $\mathrm{N}^{\circ}$ 2). En términos de densidad, para todo el periodo 2003-2015, se alcanzan las 6,25 desposesiones de vivienda por hectárea ( $\mathrm{D} / \mathrm{Ha})$.

Lo primero que constatan estas cifras es el predominio de los desahucios de inquilinos (91\%) sobre las ejecuciones hipotecarias. Para interpretar este hecho hay que considerar dos circunstancias. Por un lado considerar que en un espacio tan consolidado como el casco antiguo de la ciudad las promociones de viviendas para la venta no son tan abundantes como en el extrarradio suburbano y, en consecuencia, tampoco lo son las hipotecas vinculadas a tales promociones. Por otro lado hay que tener presente que los alquileres son más proclives a una eventual subida ante una revalorización urbana de la zona ya que las condiciones de los contratos de alquiler son más fácilmente modificables que las de las hipotecas.

\section{Cuadro $\mathrm{N}^{\circ} 2$}

Desahucios y ejecuciones hipotecarias en el Centro Histórico de Palma (2003-2014)

\begin{tabular}{|l|r|r|r|r|r|r|}
\cline { 2 - 7 } \multicolumn{1}{c|}{} & \multicolumn{2}{c|}{$2003-2007$} & \multicolumn{2}{c|}{$2008-2014$} & \multicolumn{2}{c|}{ Total } \\
\cline { 2 - 7 } \multicolumn{1}{c|}{} & Número & \multicolumn{1}{c|}{$\%$} & Número & \multicolumn{1}{c|}{$\%$} & Número & \multicolumn{1}{c|}{$\%$} \\
\hline Desahucios de inquilinos & 318 & 35,73 & 492 & 55,28 & 810 & 91,01 \\
\hline Ejecuciones hipotecarias & 17 & 1,91 & 63 & 7,08 & 80 & 8,99 \\
\hline Total & 335 & 37,64 & 555 & 62,36 & 890 & 100,00 \\
\hline
\end{tabular}

Fuente: Elaboración propia a partir de fuentes judiciales.

Los lanzamientos de inquilinos y las ejecuciones hipotecarias que hemos analizado, entre los años 2003 y 2014, concentran su epicentro en la parte centro oriental del casco antiguo (Figura $N^{\circ} 8$ ), en el punto de contacto entre la zona reformada de "la Gerreria" y la parte comercial de Sindicat/plaça Major, muy vinculado a la iniciativa lanzada por los empresarios de bares y restauración de la zona y el Ayuntamiento de Palma que se conoce como "ruta martiana".

\section{Desposesión de vivienda por revalorización en Palma}

La generación y captura de renta urbana tanto a través del circuito secundario (capital fijo inmobiliario) como a través del primario (actividad turística) (Harvey, 1982) implíca el desplazamiento, directo o indirecto, de los estratos de población que no alcanzan los niveles económicos exigidos por los nuevos usos tanto residenciales como turísticos. Para constatarlo se impone 
Figura $\mathrm{N}^{\circ} 8$

Localización de los desahucios y ejecuciones hipotecarias en el Centro Histórico de Palma (2003-2014)

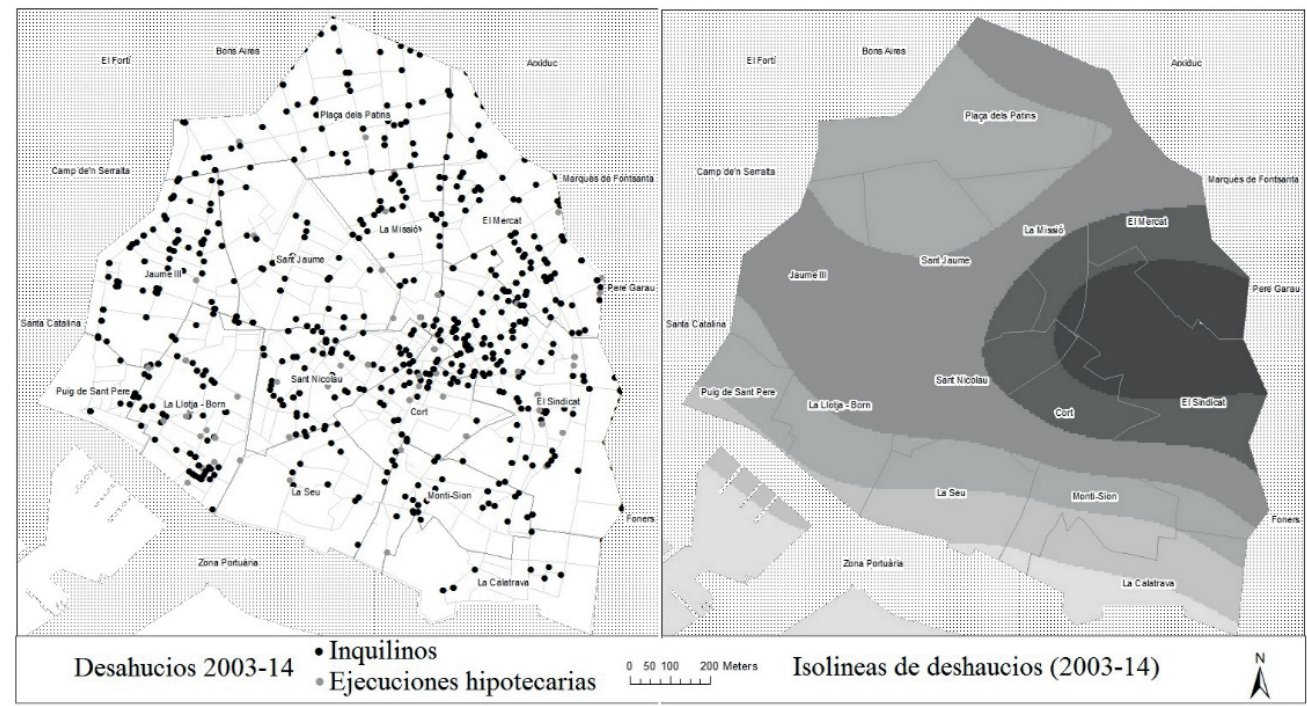

Fuente: Elaboración propia.

analizar la correlación espacial existente entre revalorización, turistización y desplazamientos directos provocados por desahucios de inquilinos y ejecuciones hipotecarias.

En primer lugar, comparando las zonas que más se han revalorizado entre 2006 y 2015 y la distribución espacial de los desahucios y las ejecuciones hipotecarias se observa una clara relación entre la revalorización inmobiliaria y la densidad de desalojos (Cuadro $N^{\circ} 3$ ) si exceptuamos las zonas más revalorizadas.

Cuadro $\mathrm{N}^{\circ} 3$

Revalorización y densidades de desposesiones en el Centro Histórico de Palma

\begin{tabular}{|l|r|r|r|}
\hline Zonas de revalorización $\left(€ / \mathrm{m}^{2}\right)$ & \multicolumn{1}{|c|}{ Desposesiones } & \multicolumn{1}{c|}{ Hectáreas } & \multicolumn{1}{c|}{ D/H } \\
\hline Entre -470 y 0 & 21 & 4,97 & 4,22 \\
\hline Entre 0 y 1.000 & 465 & 68,00 & 6,84 \\
\hline Entre 1.000 y 2.000 & 318 & 39,16 & 8,12 \\
\hline Más de 2.000 & 86 & 30,26 & 2,84 \\
\hline Total & 890 & 142,39 & 6,25 \\
\hline
\end{tabular}

Fuente: Elaboración propia.

El Cuadro N ${ }^{\circ} 3$ muestra como a más revalorización, más densidad de desposesiones, pero las dos variables corren paralelas hasta un determinado punto de revalorización en el que las desposesiones decaen. La densidad de desposesiones es menor donde la revalorización del precio 
del $\mathrm{m}^{2}$ ha sido superior a los $2.000 € / \mathrm{m}^{2}$. Excepto en este ámbito, los datos muestran una clara correlación entre revalorización y desposesiones de viviendas.

Correlacionando los datos de desposesiones directas y revalorización inmobiliaria a escala de las 19 secciones censales del Centro Histórico de Palma resulta un coeficiente de correlación prácticamente nulo $(0,09)$. Sin embargo correlacionando por separado las 13 secciones que menos se han revalorizado y, por otro, las 6 que más lo han hecho, los coeficientes de correlación entre revalorización y desahucios resultan, respectivamente, 0,86 y -0,35. En otras palabras, se da una alta correlación positiva a medida que va aumentado la revalorización y ligeramente negativa en las zonas que esta revalorización se ha hecho más clara.

En la zona sureste del casco antiguo es donde se dan los mayores incrementos de los precios inmobiliarios en el período 2006/2015 y, sin embargo, es donde la densidad de desposesiones es menor. La ausencia de lanzamientos de inquilinos y de ejecuciones hipotecarias en esta parte de la ciudad histórica debe interpretarse a la luz de la cronología de las actuaciones. El mayor número de desahucios se habría dado a partir de 1993 (fecha de modificación del Plan Especial de la Calatrava) y en 2006 ya se habría consumado la expulsión de inquilinos de la zona.

Sin embargo las estadísticas de desahucio de la zona seguro que tampoco reflejarían toda la realidad de los movimientos de población provocados por moobing inmobiliario. En 1985 el régimen de tenencia de la Calatrava era, en un 39\%, "extraño o no contesta" (Franquesa, 2010: 130). Lo que hace pensar en la inexistencia de contratos oficiales. El resto de desplazados como consecuencia de las reformas de la Calatrava en la década de 1990 se ha constatado y documentado que pudo llevarse a cabo gracias a la colaboración entre la Asociación de Vecinos del barrio y el Ayuntamiento que ayudaron con los inversores para realojar/desplazar a los inquilinos. La asociación de vecinos "facilitó la parte más difícil del proceso de rehabilitación, la de entenderse con los inquilinos", la Asociación de Vecinos, desde el Patronato de la Vivienda del ayuntamiento donde tenía un papel activo, "arregló la cuestión social yendo puerta a puerta" (Franquesa, 2010: 130). Una práctica que, en el caso de la Gerreria nos consta que llevó a cabo uno de los promotores de la actuación urbanística ${ }^{15}$. Por su parte el Ayuntamiento estableció convenios para facilitar a los inquilinos "una vivienda municipal a unos precios asequibles" (Fortuny, 1992: 105).

En conjunto, los "puerta a puerta" de promotores en el caso de la Gerreria y de la Asociación de Vecinos en el caso de "la Calatrava", "limpiaron" socialmente la zona para que los promotores pudieran poner en marcha sus proyectos. Por esta razón los datos de desposesiones por resolución judicial de la zona son menores de lo que se podría esperar aunque, previamente, los desplazamientos fueran también notables.

Y en segundo lugar, si comparamos la implantación del alojamiento turístico, especialmente el que se comercializa bajo la fórmula de Airbnb, del Centro Histórico de Palma con el de desahucios observamos también una clara correlación. Ello puede constatarse en el mapa de la Figura $N^{\circ} 9$ donde se observa una clara coincidencia de localización en la zona centro-oriental. De hecho si correlacionamos a escala de los trece barrios en que divide el Ayuntamiento de Palma el casco antiguo de la ciudad se dan correlaciones positivas $(0,74$ y 0,75$)$ entre viviendas que ofrecen Airbnb

Unidad de Actuación Urbanística de l'Estel Nou. 
y desposesiones de inquilinos y ejecuciones hipotecarias. El alojamiento turístico, especialmente el Airbnb, es un uso que compite con el alojamiento de los residentes que se ven desplazados al no poder competir con los precios que se alcanzan en esta modalidad.

Figura $\mathrm{N}^{\circ} 9$

Alojamiento turístico y desahucios en el Centro Histórico de Palma

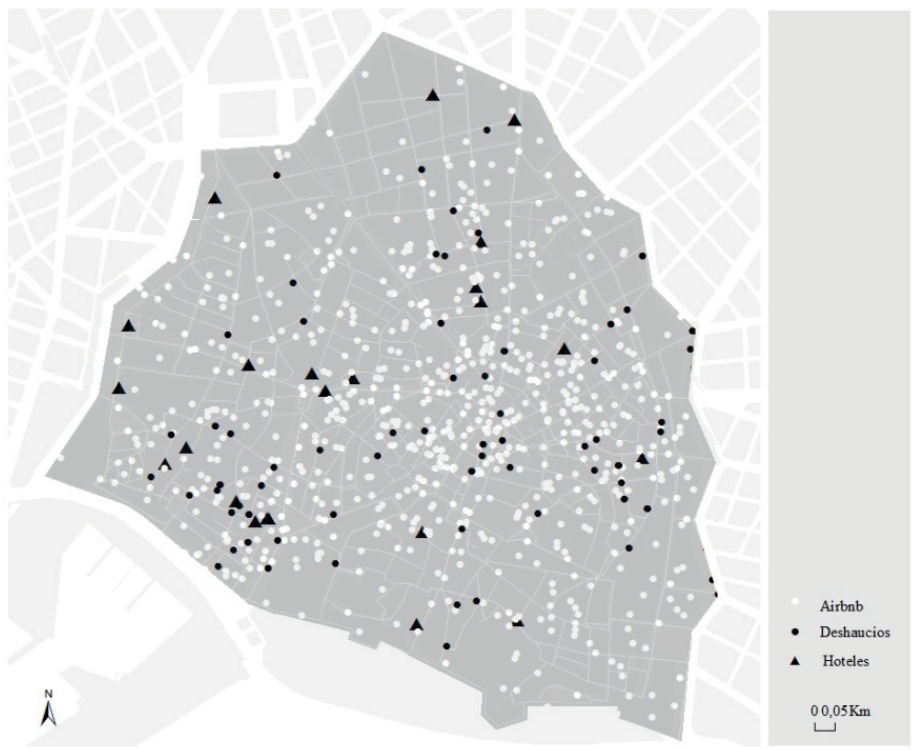

Fuente: Elaboración propia.

\section{Conclusiones}

Con el estudio empírico del Centro Histórico de Palma hemos podido observar algunas de las relaciones entre turistización, revalorización y desplazamientos directos de vivienda. Éstas pueden validar la hipótesis que se plantea en referencia al vínculo establecido entre dichos procesos. La turistización como elemento de creación de expectativas de renta, por tanto, potenciadora de la rent gap y en consecuencia de la revalorización inmobiliaria, representa un factor fundamental en la generación de desplazamientos directos, en este caso desahucios.

En este sentido, una vez establecida la correlación entre la turistización y la revalorización en el período histórico indicado, se correlaciona también la revalorización con los desplazamientos directos. Para el caso del Centro de Palma, cuanto más alta ha sido la revalorización, más desposesiones de vivienda han tenido lugar, excepto en las zonas más caras y exclusivas del SE. De tal manera que la mayor densidad de desposesiones se localiza en el área más cercana a la de mayor revalorización, es decir, en la zona con más presión de futura revalorización. No obstante, las zonas más revalorizadas presentan densidades de desposesiones mínimas, debido a que el proceso de gentrificación ya está consolidado y los desplazamientos ya se habrían producido en fases anteriores al del periodo de estudio. A medida que vaya avanzando la oleada de revalorización es de suponer que se desplazará la ola de desposesiones en la misma dirección de las revalorizaciones. 
Siendo así, podemos afirmar que las desposesiones de vivienda regulan la creación y apropiación de renta urbana, provocando que, en un determinado barrio, pueda hacerse efectiva, se pueda capitalizar, su máximo potencial de renta. Ello tiene lugar ya que los residentes con una capacidad adquisitiva inferior a la de los residentes potenciales son desplazados. En este sentido la concentración de desposesiones, en espacios construidos de alto valor patrimonial, representa una puerta y un indicador de gentrificación a corto plazo.

Sin embargo, todo el proceso reciente de desahucios no se puede entender sin tener en cuenta el proceso de financiarización del entorno construido como estrategia de producción de renta urbana. En el contexto del capitalismo financiarizado, los desplazamientos no sólo aparecen para la renovación urbana en forma de expulsiones del barrio para un proyecto puntual, sino por la necesidad de los capitales financieros de renovar los barrios. Si antes de que estallara la burbuja el proceso consistía en expulsar a la gente y luego sustituirla con clases medias, con la crisis son las revalorizaciones, vinculadas al propio proceso de financiarización, lo que ha expulsado a la población con niveles de renta que no alcanza el potencial de otros estratos sociales. Ahora los desplazamientos no tienen los mismos mecanismos de expulsión que en otras formas de capitalismo, pero tienen las mismas raíces. Es decir, los desahucios de inquilinos y ejecuciones hipotecarias no son más que la forma actual de llevar a cabo los desplazamientos que permitirán crear y capturar nueva renta urbana, un proceso que al final lo que hace es profundizar en la creación de nuevas geografías urbanas desiguales a través de estos nuevos mecanismos de apropiación de la renta urbana.

\section{Referencias bibliográficas}

ALOMAR, G. La reforma de Palma. Hacia la renovación de una ciudad a través de un proceso de evolución creativa. Palma: Banca March/COAB/Govern de les IllesBalears, 2000.

AGARWAL, S.; BALL, R.; SHAW, G. \& WILLIAMS, A. M. Thegeography of tourismproduction: unevendisciplinarydevelopment. TourismGeographies, 2000, Vol. 2, № 3, p. 241-263.

ATKINSON, R. Measuring gentrification and displacement in Greater London. Urban Studies, 2000, Vol. 37, No 1, p. 149-65.

CLARK, E. The Rent Gap Re-examined. Urban Studies, 1995, Vol. 32, № 9, p. 1489-1503.

CLARK, E. \& HANSEN, A. Financialization, rescaling rent gaps and land grabbing. 2012. Disponible en Internet: http://backdoorbroadcasting.net/2012/05/eric-clarke-and-anders-lund-hansen-financialization-rescaling-rent-gaps-and-land-grabbing/

COLAU, A. y ALEMANY, A. Vidas hipotecadas. De la burbuja inmobiliaria al derecho a la vivienda. Barcelona: Cuadrilátero de libros.2012.

ESCARTÍN, J.M. La ciutatamuntegada. Indústria del calçat, desenvolupamenturbà i condicions de vida de la Palma contemporània (1840-1940). Palma: Documenta Balear, 2001. 
FORTUNY, T. La rehabilitación del Centro Histórico de la ciudad de Palma de Mallorca. En:Jornadas de Rehabilitación. Intervención en el Centro Histórico. Palma: Col-legi Oficial d'Arquitectes de les Balears, 1992, p. 101-110.

FRANQUESA, J. Sa Calatrava mon amour. Etnografia d'un barri atrapat en la geografia del capital. Palma: Edicions Documenta Balear, 2010.

HARVEY, D. Limits to Capital. London: Verso, 1982.

HARVEY, D. The New Imperialism. Oxford: Oxford University Press, 2003.

IOANNIDES, D. Strengtheningthe ties betweentourismandeconomicgeography: a theoretical agenda. The professional geographer, 1995, Vol. 47, No 1, p. 49-60.

KRIPPNER, G. The Financialization of the American Economy. Socio-Economic Review, 2005, № 3, p. 173-208.

MARCUSE, P. Gentrification, abandonment and displacement: connections, causes and policy responses in New York City. Journal of Urban and Contemporary Law, 1985, № 28, p. 195- 240.

MARCUSE, P. On gentrification. A note from Peter Marcuse. City. Analysis of urban trends, culture, theory, policy, action, 2010, Vol. 14, N 1, p. 187-188.

MARX, K. La llamada acumulación originaria. En: El capital, Vol . 1, 1990 [1864].

MÉNDEZ, R.; ABAD, L. y PLAZA, J. Geografía de las ejecuciones hipotecarias en España. Estudios de la Fundación $1^{\circ}$ de Mayo, 2014, No 84, p. 1-41.

MIDNIGHT NOTES COLLECTIVE. Introduction to the new enclosures. The Commoner, 1990. Disponible en Internet: http://www.commoner.org.uk/02midnight.pdf

NEWMAN, K. \& E. WYLY. The right to stay put, revisited: gentrification and resistance to displacement in New York City. Urban Studies, 2006, Vol. 43, N 1, p. 23-57.

OBESO, Í. Análisis geográfico de los desahucios en España. Ería, 2014, Nº 95, p. 327-342.

SLATER, T. La expulsión de las perspectivas críticas en la investigación sobre gentrificación. En: El mercado contra la ciudad. Sobre globalización, gentrificación y políticas urbanas. Madrid: Traficantes de Sueños, 2015, p. 107-144.

SMITH, N. Toward a Theory of Gentrification a Back to the City Movement by Capital, not People. Journal of the American Planning Association, 1979, Vol. 45, N 4, p. 538-548.

SMITH, N. The New Urban Frontier: Gentrification and the Revanchist City. London: Routledge, 1996. 
SMITH, N. La nueva frontera urbana. Ciudad revanchista y gentrificación. Madrid: Traficantes de Sueños, 2012.

TREMBLAY, P. The economic organization of tourism. Annals of Tourism Research, 1998, Vol. 25, $N^{\circ} 4$ p. 837-859.

VIVES, S. L' espai urbà del capitalisme. La construcció del projecte neoliberal de Palma. Palma: Tesis doctoral de la Universitat de les Illes Balears, 2012.

VIVES-MIRÓ, S.; GONZÁLEZ-PÉREZ, J. M. \& RULLAN, O. Home dispossession: the uneven geography of evictions in Palma (Majorca). Die Erde, 2015, Vol. 146, N 2-3, p. 113-126.

VIVES-MIRÓ, S. y RULLAN, O. La vivienda en el tránsito de la reproducción ampliada del capital a la acumulación por desposesión en España. En: XII Coloquio y Trabajos de Campo del Grupo de Geografía Urbana (AGE), Territorios inconclusos y Sociedades Rotas. Madrid: Asociación de Geógrafos Españoles, 2014, p. 1-16. 
